\title{
Synthesis and Chemical Properties of $\operatorname{Poly}(N$-substituted diphenylamine-4,4'-diyl $)$ s
}

\author{
By Takakazu YАмамото, ${ }^{*}$ Sang-Bum KIM, and Take-aki KoIZUMI
}

A series of poly(diphenylamine)s with substituents at the $N$-position, $\left(\mathrm{C}_{6} \mathrm{H}_{4}-p-\mathrm{NR}-\mathrm{C}_{6} \mathrm{H}_{4}-p\right)_{\mathrm{n}}(\mathrm{R}=$ methyl, butyl, hexyl, and benzoyl), were prepared by organometallic polycondensation using a zerovalent nickel complex. These polymers were soluble in organic solvents such as THF, $N$-methylpyrrolidone (NMP), and trifluoroacetic acid (TFA), and gave intrinsic viscosity of $0.52-0.93 \mathrm{dL} \mathrm{g}^{-1}$. They showed number average molecular weights $\left(M_{\mathrm{n}}\right)$ of $3400-6100$ with $M_{\mathrm{w}} / M_{\mathrm{n}}\left(M_{\mathrm{w}}=\right.$ weight average molecular weight) of 1.9-2.4 in GPC analysis. The polymers exhibited photoluminescence (PL) with emission peaks at $\lambda_{\mathrm{EM}}=408-425 \mathrm{~nm}$ in NMP solutions.

KEY WORDS: Poly(diphenylamine) / Organometallic Polycondensation / Conductivity / Optical Properties /

Much attention has been paid for polymers with electronic and optical functionalities. Poly(aniline)s $\mathrm{s}^{1-8}$ are representative conducting polymers, and many papers have been reported for applications of the polymers. Their applications to electrodes of batteries, ${ }^{2 \mathrm{a}-\mathrm{c}}$ anti-static materials, ${ }^{2 \mathrm{~d}, \mathrm{e}}$ active materials in electrochromic displays, ${ }^{3}$ and corrosion inhibitors ${ }^{4}$ have been carried out. Previously, we reported synthesis of poly(diphenylamine-4,4'-diyl) (P(DPA)-Ni) by organometallic polycondensation of 4,4'-dibrominated diphenylamine (DPA) using an $\mathrm{Ni}(0)$ complex, $\mathrm{Ni}(0) \mathrm{L}_{\mathrm{m}},{ }^{5}$ as a condensing agent.

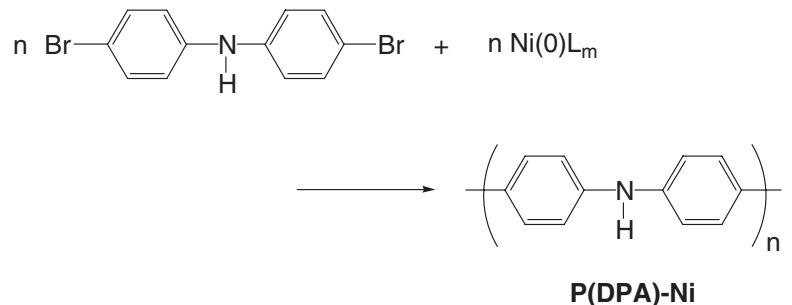

P(DPA)-Ni had chemical properties different from those of P(DPA)-Ox, which was prepared by oxidative polymerization of $\mathrm{C}_{6} \mathrm{H}_{5} \mathrm{NHC}_{6} \mathrm{H}_{5} .{ }^{6 a} \mathbf{P}(\mathbf{D P A})-\mathrm{Ni}$ is considered to have a welldefined linear structure shown in eq 1 , because the $\mathrm{Ni}(0) \mathrm{L}_{\mathrm{m}}$ promoted polycondensation occurs selectively at the $\mathrm{C}-\mathrm{Br}$ bond. $^{5 \mathrm{c}}$ On the other hand, P(DPA)-Ox seems to contain structural irregularities because the oxidative polymerization can take place at various $\mathrm{C}-\mathrm{H}$ positions of the phenyl group and at the NH group. P(DPA)-Ox was considered to contain at least two isomeric units, $-\mathrm{C}_{6} \mathrm{H}_{4}-\mathrm{NH}-\mathrm{C}_{6} \mathrm{H}_{4}-$ and $-\mathrm{C}_{6} \mathrm{H}_{4}-\mathrm{N}\left(\mathrm{C}_{6} \mathrm{H}_{5}\right)-$, in the polymer main chain. ${ }^{6}$

Oxidative polymerization of $\mathrm{N}$-substituted diphenylamine has also been reported, ${ }^{6 \mathrm{a}-\mathrm{d}, 7,8 \mathrm{e}}$ and basic chemical properties of the obtained P(N-R-DPA)-Ox have been reported. However, synthesis of $N$-substituted diphenylamine via organometallic polycondensation has received less attention. P( $N$-R-DPA)-Ox is usually obtained in a p-doped oxidized state and some chemical treatment is usually needed to yield the polymer in a neutral state. By contrast, the organometallic polycondensation gives the polymer (e.g., P(N-R-DPA)-Ni by using $\left.\mathrm{Ni}(0) \mathrm{L}_{\mathrm{m}}\right)$ in a neutral state, and studies of the polymer obtained by organometallic polycondensation are considered to be intriguing. The intrinsically neutral P( $N$-R-DPA)-Ni would be a useful material for electronic and optical applications (e.g., as a hole-transporting material in organic light emitting diodes). In this paper, we report preparation of polymers of diphenylamines, $\left(\mathrm{C}_{6} \mathrm{H}_{4}-p-\mathrm{NR}-\mathrm{C}_{6} \mathrm{H}_{4}-p\right)_{\mathrm{n}}$, with the alkyl or benzoyl substituents (R) at the $N$-position via organometallic polycondensation similar to that expressed by eq 1 . The obtained polymers showed high solubility in organic solvents and high thermal stability in TGA analysis.

\section{EXPERIMENTAL}

\section{Materials and Measurements}

${ }^{1} \mathrm{H}$ NMR and IR spectra were recorded on a JEOL FX-100 or EX-400 spectrometer and a JASCO IR 810 spectrophotometer, respectively. UV-vis and photoluminescence (PL) spectra were measured with a JASCO Ubent-35 spectrometer and a Hitachi F-4010 spectrophotometer, respectively. Elemental analysis was carried out by the Center for Advanced Materials Analysis (Suzukakedai) in Tokyo Institute of Technology. Molecular weight measurement was carried out with a Toso HLC-810 gel permeation chromatograph (eluent = DMF; polystyrene standards). Instrinsic viscosity was measured in NMP with an Ubbelohde viscometer at $30^{\circ} \mathrm{C}$. Thermal analysis was performed with a Shimadzu TA-50 WS thermal analyzer equipped with a Shimadzu DSC-50 differential scanning calorimeter and a Shimadzu TGA-50 thermogravimetric analyzer. Conductivity measurement was carried out by a two-probe method using a Sanwa CDS-820 digital multimeter. Iodine doping was carried out by exposure of a polymer powder to the vapor of iodine in a vacuum line. Excess iodine was removed under vacuum. The powder was collected by 
filtration and dried under vacuum. These doped samples were pressed into pellets at about $2 \times 10^{8} \mathrm{~Pa}$. From the pellet, a bar is obtained by cutting the pellet, and carbon paste was put at both ends of the bar to measure the electrical conductivity. Bis(1,5-cyclooctadiene)nickel(0), [Ni(cod $\left.)_{2}\right],{ }^{9} 4,4^{\prime}$-dibromodiphenylamine (DPA-Br 2 ), ${ }^{10}$ and $N$-hexyl-4,4'-dibromodiphenylamine $(\boldsymbol{N} \text {-Hex-DPA-Br })^{7 b}$ were prepared according to the literature.

\section{Synthesis of Monomers}

Synthesis of $N$-methyl-4,4'-dibromodiphenylamine ( $N$-MeDPA-Br $\mathbf{r}_{2}$. $\mathrm{N}$-Me-DPA-Br $\mathbf{r}_{2}$ was prepared by bromination of methyldiphenylamine in a way analogous to that applied for the preparation of DPA-Br ${ }_{2} ;{ }^{10}$ Anal. Calcd for $\mathrm{C}_{13} \mathrm{H}_{11} \mathrm{Br}_{2} \mathrm{~N}$ : C, 45.8; H, 3.3; N, 4.1\%. Found: C, 46.2; H, 3.1; N, 4.2\%. IR (KBr): 3025, 2921, 1599, 1490, 1362, 1247, 1182, 814, 799 $\mathrm{cm}^{-1} .{ }^{1} \mathrm{H} \mathrm{NMR}\left(\mathrm{CDCl}_{3}\right): \delta$ 6.8-7.4 (m, aromatic, $\left.8 \mathrm{H}\right), 3.25$ (s, $\left.\mathrm{NCH}_{3}, 3 \mathrm{H}\right)$. UV-vis $\left(\mathrm{CHCl}_{3}\right): \lambda_{\max }=297 \mathrm{~nm}$.

Synthesis of $N$-butyl-4, $4^{\prime}$-dibromodiphenylamine ( $N$-Bu-DPA$\left.\mathbf{B r}_{2}\right)$. To a THF-1,4-dioxane $(1: 1 \mathrm{v} / \mathrm{v}, 300 \mathrm{~mL})$ mixed solution containing dispersed sodium hydride $(0.684 \mathrm{~g}, 17.1 \mathrm{mmol})$ was added a THF solution ( $5 \mathrm{~mL}$ ) of 4,4'-dibromodiphenylamine $(5 \mathrm{~g}, 15.3 \mathrm{mmol})$ and 1-bromobutane $(2.9 \mathrm{~g}, 21.4 \mathrm{mmol})$. The solution was refluxed for $12 \mathrm{~h}$, and then cooled to room temperature. The volatile materials were removed under vacuum, and $\mathrm{CHCl}_{3}(50 \mathrm{~mL})$ and water $(50 \mathrm{~mL})$ were added to the residue. The organic phase was separated and washed with an aqueous solution of sodium carbonate $(100 \mathrm{~mL})$. After removal of the solvent by evaporation, the crude product was purified by column chromatography on $\mathrm{SiO}_{2}$ (eluent $=1: 1$ mixture of hexane and ethyl acetate) and dried under vacuum to give $\boldsymbol{N}$-Bu-DPA-Br 2 as a colorless oil (64\%). Anal. Calcd for $\mathrm{C}_{16} \mathrm{H}_{17} \mathrm{Br}_{2} \mathrm{~N}$ : C, 50.2; H, 4.5; N, 3.7\%. Found: C, 50.8; H, 4.8; N, 3.4\%. IR (KBr): 3025, 2920, 2854, 1599, 1490, 1362, $1247,1182,814,799 \mathrm{~cm}^{-1} .{ }^{1} \mathrm{H}$ NMR $\left(\mathrm{CDCl}_{3}\right): \delta 7.36-6.84(\mathrm{~m}$, aromatic, $8 \mathrm{H}), 3.68\left(\mathrm{t}, \mathrm{NCH}_{2}, 2 \mathrm{H}\right), 1.7-1.4\left(\mathrm{~m}, \mathrm{~N}\left(\mathrm{CH}_{2}\right)_{2}-, 2 \mathrm{H}\right)$, 0.92 (t, $\left.\mathrm{CH}_{3}, 3 \mathrm{H}\right)$. UV-vis $\left(\mathrm{CHCl}_{3}\right): \lambda_{\max }=305 \mathrm{~nm} .{ }^{5 \mathrm{~d}}$ Similar synthesis of $\mathbf{N}$-Bu-DPA-Br $\mathbf{r}_{2}$ has been reported. ${ }^{6 \mathrm{a}}$

Synthesis of $N$-benzoyl-4,4'-dibromodiphenylamine ( $N$-BzDPA-Br ${ }_{2}$ ). $\boldsymbol{N}$-Bz-DPA-Br $\mathbf{r}_{2}$ was prepared analogously from DPA-Br $_{2}$ and $\mathrm{PhCOCl}$; Yield, 77\%. Anal. Calcd for $\mathrm{C}_{19} \mathrm{H}_{13} \mathrm{Br}_{2} \mathrm{NO}$ : C, 52.9; H, 3.0; N, 3.3\%. Found: C, 53.1; H, 3.1; N, 3.3\%. IR (KBr): 3053, 1653, 1562, 1481, 1396, 1322, $1290,1101,1063,1006,810,778 \mathrm{~cm}^{-1} \cdot{ }^{1} \mathrm{H}$ NMR $\left(\mathrm{CDCl}_{3}\right): \delta$ 7.5-6.9 (m, aromatic, $13 \mathrm{H})$. UV-vis $\left(\mathrm{CHCl}_{3}\right): \lambda_{\max }=256 \mathrm{~nm}$.

\section{Synthesis of Polymers}

Poly( $N$-methyldiphenylamine-4,4' -diyl) (P( $N$-Me-DPA)-Ni). To a dry DMF solution $(25 \mathrm{~mL})$ of $\mathrm{Ni}(\operatorname{cod})_{2}(1.93 \mathrm{~g}, 7.03 \mathrm{mmol})$, 1,5-cyclooctadiene $(1.5 \mathrm{~mL})$, and 2,2'-bipyridyl $(1.10 \mathrm{~g}, 7.03$ mmol) was added $\mathbf{N}$-Me-DPA-Br $2(2.0 \mathrm{~g}, 5.86 \mathrm{mmol})$, and the mixture was stirred at $60^{\circ} \mathrm{C}$. After $16 \mathrm{~h}$, the reaction mixture was poured into an aqueous solution of ammonia. The yellow-green powder was collected by filtration, and washed with diluted hydrochloric acid, a warm aqueous solution of disodium ethylenediaminetetraacetate ( $\mathrm{Na}_{2}$ EDTA), diluted aqueous am- monia, water, and methanol successively. Drying the remaining powder under vacuum for $24 \mathrm{~h}$ gave P(N-Me-DPA)-Ni in $87 \%$ yield. Removal of by-products (e.g., Ni compounds) by washing was accomplished rather easily and an ash-free polymer was obtained. Anal. Calcd for $\left[\mathrm{C}_{13} \mathrm{H}_{11} \mathrm{~N} \cdot\left(\mathrm{H}_{2} \mathrm{O}\right)_{0.3}\right]_{\mathrm{n}}$ : C, 83.7; H, 6.3; N, 7.5\%. Found: C, 83.5; H, 6.2; N, 7.6; Br, 0; ash, 0\%. IR (KBr): 3018, 2890, 2842, 1596, 1498, 1345, 1246, 1172, 822, $791 \mathrm{~cm}^{-1} .{ }^{1} \mathrm{H} \mathrm{NMR}\left(\mathrm{CF}_{3} \mathrm{CO}_{2} \mathrm{D}, 400 \mathrm{MHz}\right): \delta$ 7.6-7.1 $(\mathrm{m}$, aromatic, $8 \mathrm{H}), 3.38\left(\mathrm{~s}, \mathrm{NCH}_{3}, 3 \mathrm{H}\right) .{ }^{13} \mathrm{C}\left\{{ }^{1} \mathrm{H}\right\} \mathrm{NMR}\left(\mathrm{CF}_{3} \mathrm{CO}_{2} \mathrm{D}\right.$, $100 \mathrm{MHz}): \delta 146.2,142.1,130.4,122.8,63.5$. UV-vis (NMP): $\lambda_{\max }=347 \mathrm{~nm}$.

Poly( $N$-butyldiphenylamine-4,4' -diyl) (P(N-Bu-DPA)-Ni). $\quad \mathbf{P}(N-$ Bu-DPA)-Ni was prepared analogously; Yield, 82\%. Anal. Calcd for $\left[\mathrm{C}_{16} \mathrm{H}_{17} \mathrm{~N} \cdot\left(\mathrm{H}_{2} \mathrm{O}\right)_{0.2}\right]_{\mathrm{n}}$ : C, 84.7; H, 7.7; N, 6.2\%. Found: C, 84.8; H, 7.5; N, 6.2; Br, 0; ash, 0\%. IR (KBr): 3028, 2920, 2854, 1599, 1490, 1362, 1247, 1182, 814, $799 \mathrm{~cm}^{-1}$. ${ }^{1} \mathrm{H}$ NMR $\left(\mathrm{CDCl}_{3}, 400 \mathrm{MHz}\right): \delta 7.5-7.0(\mathrm{~m}$, aromatic, $8 \mathrm{H}), 3.76$ $\left(\mathrm{t}, \mathrm{NCH}_{2}, 2 \mathrm{H}\right), 1.7-1.2\left(\mathrm{~m}, \mathrm{NCH}_{2}\left(\mathrm{CH}_{2}\right)_{2-}, 4 \mathrm{H}\right), 0.96\left(\mathrm{t}, \mathrm{CH}_{3}\right.$, $3 \mathrm{H}) .{ }^{13} \mathrm{C}\left\{{ }^{1} \mathrm{H}\right\} \mathrm{NMR}\left(\mathrm{CF}_{3} \mathrm{CO}_{2} \mathrm{D}, 100 \mathrm{MHz}\right): \delta 146.7,133.5$, 127.3, 121.1, 52.2, 29.7, 20.3, 13.9. UV-vis (NMP): $\lambda_{\max }=$ $358 \mathrm{~nm}$.

Poly( $N$-hexyldiphenylamine-4,4'-diyl) (P(N-Hex-DPA)-Ni). $\quad \mathbf{P}(N-$ Hex-DPA)-Ni was prepared in an analogous way; Yield, $88 \%$. Anal. Calcd for $\left[\mathrm{C}_{18} \mathrm{H}_{21} \mathrm{~N} \cdot\left(\mathrm{H}_{2} \mathrm{O}\right)_{0.2}\right]_{\mathrm{n}}: \mathrm{C}, 84.8 ; \mathrm{H}, 8.5 ; \mathrm{N}, 5.5 \%$. Found: C, 84.7; H, 8.5; N, 5.5; Br, 0; ash, 0\%. IR (KBr): 3028, 2920, 2854, 1599, 1490, 1362, 1247, 1182, 814, $799 \mathrm{~cm}^{-1}$. ${ }^{1} \mathrm{H}$ NMR $\left(\mathrm{CF}_{3} \mathrm{CO}_{2} \mathrm{D}, 400 \mathrm{MHz}\right): \delta 7.92-7.74(\mathrm{~m}$, aromatic, $8 \mathrm{H})$, $4.36\left(\mathrm{t}, \mathrm{NCH}_{2}, 2 \mathrm{H}\right), 1.86\left(\mathrm{~m}, \mathrm{NCH}_{2} \mathrm{CH}_{2}, 2 \mathrm{H}\right), 1.53(\mathrm{~m}$, $\left.\mathrm{NCH}_{2} \mathrm{CH}_{2} \mathrm{CH}_{2}, 2 \mathrm{H}\right), 1.42$ (m, $\left.\mathrm{NCH}_{2} \mathrm{CH}_{2} \mathrm{CH}_{2} \mathrm{CH}_{2} \mathrm{CH}_{2}, 4 \mathrm{H}\right)$, $0.95\left(\mathrm{t}, \mathrm{CH}_{3}, 3 \mathrm{H}\right) .{ }^{13} \mathrm{C}\left\{{ }^{1} \mathrm{H}\right\} \mathrm{NMR}\left(\mathrm{CF}_{3} \mathrm{CO}_{2} \mathrm{D}, 100 \mathrm{MHz}\right): \delta$ 143.5, 141.9, 131.1, 123.5, 61.6, 31.9, 26.7, 23.0, 13.3. UV-vis (NMP): $\lambda_{\max }=366 \mathrm{~nm}$.

Poly( $N$-benzoyldiphenylamine-4, $4^{\prime}$-diyl) (P(N-Bz-DPA)-Ni). $\quad \mathbf{P}(N-$ Bz-DPA)-Ni was prepared in an analogous way; Yield, 98\%. Anal. Calcd for $\left[\mathrm{C}_{19} \mathrm{H}_{13} \mathrm{NO} \cdot\left(\mathrm{H}_{2} \mathrm{O}\right)_{0.4}\right]_{\mathrm{n}}$ : C, 81.9; H, 5.0; N, $5.0 \%$. Found: C, 81.8; H, 4.8; N, 5.2; Br, 0; ash, 0\%. IR (KBr): 3031, 1658, 1599, 1491, 1331, 1298, 1012, 817, $782 \mathrm{~cm}^{-1} .{ }^{1} \mathrm{H}$ NMR $\left(\mathrm{CF}_{3} \mathrm{CO}_{2} \mathrm{D}, \quad 400 \mathrm{MHz}\right): \quad \delta \quad 7.8-7.3 \quad(\mathrm{~m}, \quad$ aromatic, $13 \mathrm{H})$. ${ }^{13} \mathrm{C}\left\{{ }^{1} \mathrm{H}\right\} \mathrm{NMR}\left(\mathrm{CF}_{3} \mathrm{CO}_{2} \mathrm{D}, 100 \mathrm{MHz}\right): \delta 177.4,143.5,142.3$, 133.6, 130.7, 130.3, 129.7, 129.2, 128.3. UV-vis (NMP): $\lambda_{\max }=$ $310 \mathrm{~nm}$.

\section{RESULTS AND DISCUSSION}

\section{Polymer Synthesis}

Dehalogenative polycondensation of $\mathrm{N}$-R-DPA-Br 2 using the $\mathrm{Ni}(0)$ complex gave the corresponding poly $(N$-substituted diphenylamine-4, $4^{\prime}$-diyl) (P( $\boldsymbol{N}$-R-DPA)-Ni), as shown in Scheme 1 . The polymers were obtained as a yellow powder in good yields (82-98\%), and they were worked-up by washing with an aqueous solution of $\mathrm{Na}_{2}$ EDTA to remove $\mathrm{Ni}$ compounds. Table I summarizes the results of polymerization. The data from elemental analysis of the polymers agreed with partially hydrated (e.g., $0.2 \mathrm{H}_{2} \mathrm{O}$ per the repeating unit) polymers. The $-\mathrm{C}_{6} \mathrm{H}_{4}-p-\mathrm{N}(\mathrm{R})-\mathrm{C}_{6} \mathrm{H}_{4}-p$-unit is considered to be intact during the polymerization even for the benzoyl- 


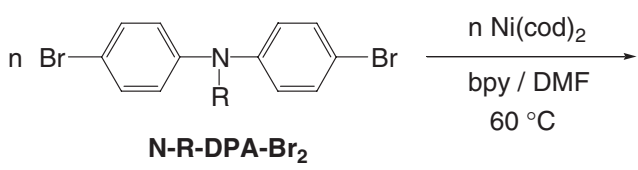

$\mathrm{R}=$ methyl, butyl, hexyl, benzoyl

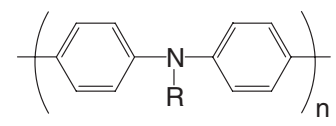

P(N-Me-DPA)-Ni ( $R=$ methyl) P(N-Bu-DPA)-Ni (R= butyl) P(N-Hex-DPA)-Ni (R = hexyl) P(N-Bz-DPA)-Ni ( $\mathrm{R}=$ benzoyl)

Scheme 1. Preparation of P(N-R-DPA)-Ni.

Table I. Results of preparation of P(N-R-DPA)-Nis ${ }^{a}$

\begin{tabular}{lccccc}
\hline \multicolumn{1}{c}{ Polymer } & yield $/ \%$ & $M_{\mathrm{n}}{ }^{\mathrm{b}}$ & $M_{\mathrm{w}}{ }^{\mathrm{b}}$ & $M_{\mathrm{w}} / M_{\mathrm{n}}{ }^{\mathrm{b}}$ & {$[\eta]^{\mathrm{c}} / \mathrm{dL} \mathrm{g}^{-1}$} \\
\hline P(DPA)-Ni & 97 & 6400 & 20000 & 3.13 & 0.66 \\
P(N-Me-DPA)-Ni & 87 & 6100 & 14500 & 2.37 & 0.52 \\
P(N-Bu-DPA $)-N i$ & 82 & 5700 & 12000 & 2.11 & 0.74 \\
P(N-Hex-DPA $)-N i$ & 88 & 5400 & 10090 & 1.87 & 0.93 \\
P(N-Bz-DPA $)-N i$ & 98 & 3400 & 8200 & 2.41 & 0.62 \\
\hline
\end{tabular}

a Polymerization was carried out in DMF at $60^{\circ} \mathrm{C}$ for $16 \mathrm{~h}$. ${ }^{\mathrm{b}}$ Determined by GPC (polystyrene standard; eluent $=$ a $0.01 \mathrm{M} \mathrm{LiBr} / \mathrm{DMF}$ solution).

cIntrinsic viscosity measured in NMP at $30^{\circ} \mathrm{C}$. ${ }^{\mathrm{d}}$ From ref $5 \mathrm{~b}$.

substituted unit. Detection of no Br suggested that the formed polymer contained a polymer-Ni terminal groups as the major terminal group, and the polymer-Ni group was converted to a polymer-H group during work-up, similar to cases of poly(heterocycles) prepared analogously. ${ }^{11}$

The relatively large $[\eta]$ for $M_{\mathrm{n}}$ of the polymers ( $c f$. Table I) suggested a stiff structure of the polymers. P(N-R-DPA)-Nis showed comparable or higher solubility than that of P(DPA)$\mathrm{Ni}$ as shown in Table II. The $\mathrm{Bu}$ and $\mathrm{Bz}$ polymers were soluble in $\mathrm{CHCl}_{3}$, whereas P(DPA)-Ni was not soluble in $\mathrm{CHCl}_{3}$. P(DPA)-Ox prepared by oxidative polymerization using diphenylamine or 4-aminobiphenyl did not have good solubility in organic solvents. ${ }^{6 e} \mathbf{P}\left(\boldsymbol{N}\right.$-R-DPA)-Oxs in a $\mathrm{BF}_{4}$-doped state were also soluble in organic solvents. ${ }^{6 \mathrm{~b}}$

Figure 1 shows comparison of IR spectra of P(N-R-DPA)Nis with that of P(DPA)-Ni. The $v(\mathrm{~N}-\mathrm{H})$ peak of P(DPA)-Ni at $3388 \mathrm{~cm}^{-1}$ reasonably disappears in the IR spectra of $\mathbf{P}(\boldsymbol{N}-\mathbf{R}-$ DPA)-Nis. P( $\boldsymbol{N}$-Bz-DPA $)$-Ni gives rise to a strong $v(\mathrm{C}=\mathrm{O})$ peak at $1658 \mathrm{~cm}^{-1}$. All the polymers show an IR peak at about

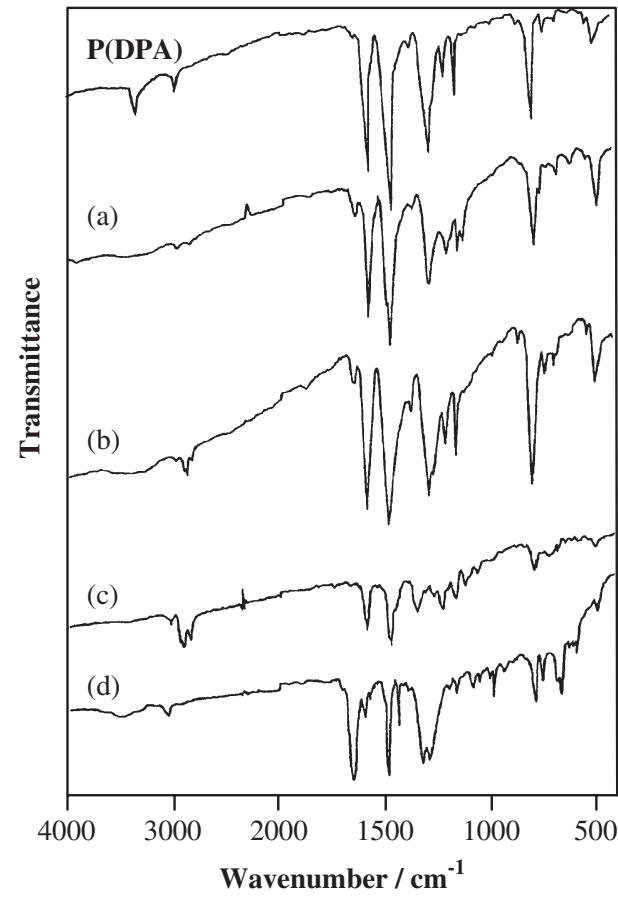

Figure 1. IR spectra of P(DPA)-Ni (from ref. $5 b$ ), (a) $\mathbf{P}(\mathbf{N}$-Me-DPA)-Ni, (b) $\mathrm{P}(\mathrm{N}$-Bu-DPA)-Ni, (c) P(N-Hex-DPA)-Ni, and (d) P(N-Bz-DPA)-Ni.

$800 \mathrm{~cm}^{-1}$, which is assigned to a $\delta(\mathrm{C}-\mathrm{H})$ peak of the $p$ phenylene unit. ${ }^{1,8 \mathrm{e}}$

NMR data of the polymers also agreed with the polymer structures. Figure 2 displays ${ }^{1} \mathrm{H}$ and ${ }^{13} \mathrm{C}\left\{{ }^{1} \mathrm{H}\right\}$ NMR spectra of $\mathbf{P}\left(\mathrm{N}\right.$-Hex-DPA)-Ni in $\mathrm{CF}_{3} \mathrm{CO}_{2} \mathrm{D}$. In the ${ }^{1} \mathrm{H}$ NMR spectrum of

Table II. Solubility of $\mathrm{P}(\mathrm{N}-\mathrm{R}-\mathrm{DPA})-\mathrm{Nis}$

\begin{tabular}{|c|c|c|c|c|c|}
\hline solvent & $\mathrm{P}(\mathrm{N}$-Me-DPA)-Ni & $\mathrm{P}(\mathrm{N}-\mathrm{Bu}-\mathrm{DPA})-\mathrm{Ni}$ & $\mathrm{P}(\mathrm{N}$-Hex-DPA)-Ni & $\mathrm{P}(N-\mathrm{Bz}-\mathrm{DPA})-\mathrm{Ni}$ & $\mathrm{P}(\mathrm{DPA})-\mathrm{Ni}^{\mathrm{a}}$ \\
\hline NMP & $S$ & $S$ & $\mathrm{~S}$ & $S$ & $S$ \\
\hline DMF & PS & $S$ & $S$ & PS & PS \\
\hline acetone & 1 & 1 & 1 & 1 & 1 \\
\hline $\mathrm{HCO}_{2} \mathrm{H}$ & I & PS & PS & I & I \\
\hline $\mathrm{CF}_{3} \mathrm{CO}_{2} \mathrm{H}$ & $S$ & $S$ & $S$ & $S$ & $S$ \\
\hline THF & PS & $S$ & $S$ & $S$ & PS \\
\hline hexane & 1 & 1 & 1 & I & 1 \\
\hline toluene & I & I & I & I & I \\
\hline DMSO & PS & PS & PS & PS & PS \\
\hline $\mathrm{CHCl}_{3}$ & 1 & $S$ & $S$ & S & 1 \\
\hline $\mathrm{MeOH}$ & 1 & 1 & I & 1 & 1 \\
\hline $\mathrm{CH}_{3} \mathrm{CN}$ & 1 & 1 & I & I & 1 \\
\hline
\end{tabular}

S: Soluble, PS: Partially soluble, I: Insoluble. ${ }^{a}$ From ref $5 b$. 
(a) ${ }^{1} \mathrm{H}$ NMR

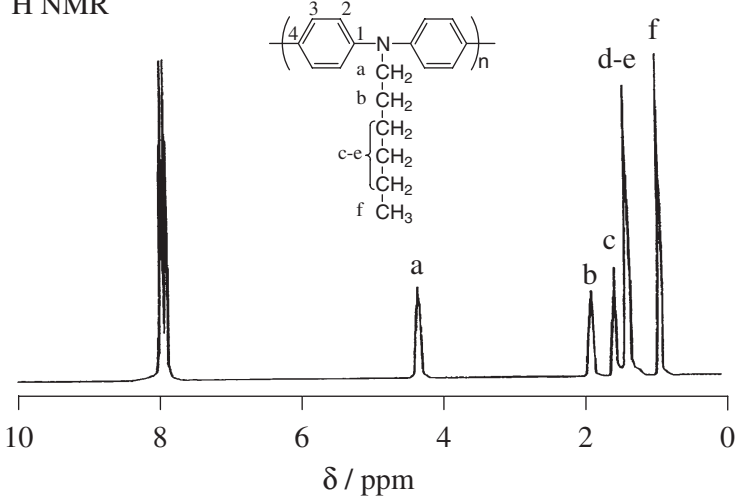

(b) ${ }^{13} \mathrm{C}\left\{{ }^{1} \mathrm{H}\right\}$ NMR

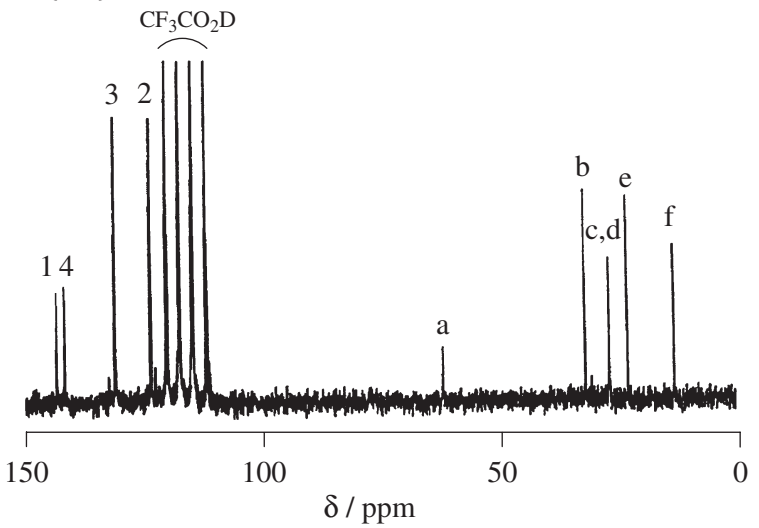

Figure 2. ${ }^{1} \mathrm{H}$ and ${ }^{13} \mathrm{C}\left\{{ }^{1} \mathrm{H}\right\} \mathrm{NMR}$ spectra of $\mathbf{P}(\mathbf{N}$-Hex-PDA $)-\mathrm{Ni}$ in $\mathrm{CF}_{3} \mathrm{CO}_{2} \mathrm{D}$.

$\mathbf{P}(\boldsymbol{N}$-Hex-DPA $)-\mathbf{N i}$, an AB quartet pattern of $p$-phenylene unit centered at $\delta 7.84$ is observed. The signals of the hexyl group are exhibited at $\delta 4.36,1.86,1.53,1.42$, and 0.95 , and the peak area ratio between the aromatic signals and the aliphatic signals agrees well with the structure of $\mathbf{P}(\boldsymbol{N}$-Hex-DPA $)-N i$. As shown in Figure $2 b$, the ${ }^{13} \mathrm{C}\left\{{ }^{1} \mathrm{H}\right\}$ NMR of $\mathbf{P}(\boldsymbol{N}$-Hex-DPA $)$-Ni shows sharp four peaks of the $p$-phenylene group at $\delta 123.5,131.1$, 141.9, and 143.5, and the hexyl signals are observed at $\delta 13.3$, 23.0, 26.7, 31.9, and 61.6. Other P( $\boldsymbol{N}$-R-DPA)-Nis also gave reasonable IR and NMR data, indicating that they had a linear main chain with well-defined bonding between the monomeric units. The ${ }^{13} \mathrm{C}\left\{{ }^{1} \mathrm{H}\right\}$ NMR spectra of $\mathbf{P}(\boldsymbol{N}$-R-DPA)-Nis are similar to reported ${ }^{13} \mathrm{C}\left\{{ }^{1} \mathrm{H}\right\}$ NMR spectra of P(N-R-DPA)Oxs,${ }^{6 a, 8 \mathrm{e}}$ revealing that $\mathbf{P}(\boldsymbol{N}$-R-DPA $)$-Oxs also have essentially linear structure as $\mathbf{P}(\boldsymbol{N}$-R-DPA $)$-Nis. ${ }^{1} \mathrm{H}$ NMR spectra of P(N-R-DPA)-Oxs have not been reported to our best knowledge.

\section{Chemical Properties}

Thermogravometric analysis (TGA) data of P(N-R-DPA)Nis are shown in Figure 3. Weight loss of the polymer starts at about $400{ }^{\circ} \mathrm{C}$ with $15-48 \%$ residual weight at $900{ }^{\circ} \mathrm{C}$ under $\mathrm{N}_{2}$. The weight loss starting temperatures were lower than that of P(DPA)-Ni (about $500^{\circ} \mathrm{C}$ ), ${ }^{5 \mathrm{~b}}$ however, the polymers still had high thermal stability.

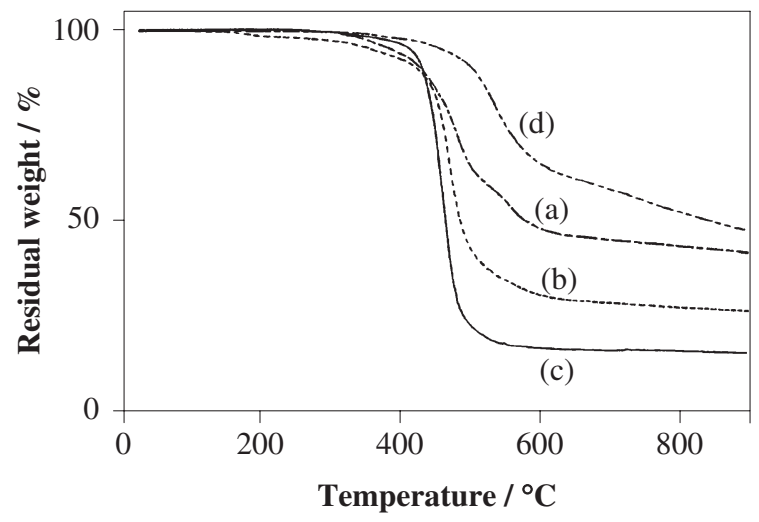

Figure 3. TGA traces of (a) $\mathbf{P}(\mathbf{N}-\mathrm{Me}-\mathrm{DPA})-\mathrm{Ni}$, (b) $\mathbf{P}(\mathbf{N}$-Bu-DPA)-Ni, (c) $\mathbf{P}(\mathbf{N}-$ Hex-DPA)-Ni, and (d) P(N-Bz-DPA)-Ni.

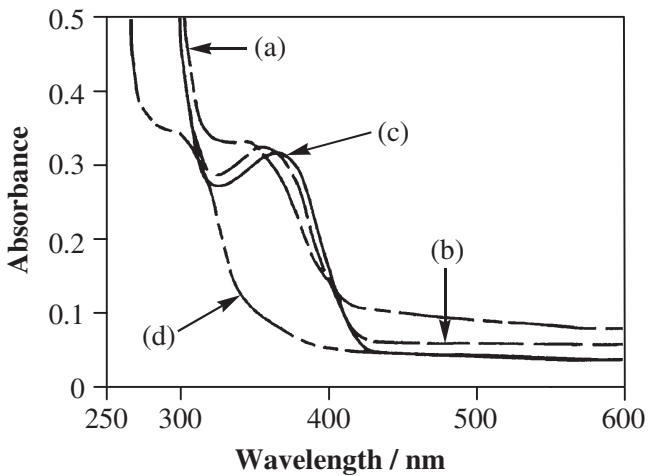

Figure 4. UV-vis spectra of (a) $\mathbf{P}(\mathbf{N}-\mathrm{Me}-\mathrm{DPA})-\mathrm{Ni}$, (b) $\mathbf{P}(\mathrm{N}-\mathrm{Bu}-\mathrm{DPA})-\mathrm{Ni}$, (c) $\mathrm{P}(\mathrm{N}-\mathrm{Hex}-\mathrm{DPA})-\mathrm{Ni}$, and (d) $\mathrm{P}(\mathrm{N}-\mathrm{Bz}-\mathrm{DPA})-\mathrm{Ni}$ in NMP.

Table III. Optical data of polymers

\begin{tabular}{ccc}
\hline Polymer & UV-vis $\left(\lambda_{\max } / \mathrm{nm}\right)^{\mathrm{a}}$ & $\mathrm{PL}\left(\lambda_{\mathrm{EM}} / \mathrm{nm}\right)^{\mathrm{a}}$ \\
\hline P(DPA)-Ni & 380 & $417,440 \mathrm{sh}$ \\
P(N-Me-DPA $)-\mathbf{N i}$ & 347 & $408,432 \mathrm{sh}$ \\
P(N-Bu-DPA)-Ni & 358 & $414,436 \mathrm{sh}$ \\
P(N-Hex-DPA)-Ni & 366 & $425,449 \mathrm{sh}$ \\
P(N-Bz-DPA)-Ni & 310 & $412,430 \mathrm{sh}$ \\
\hline
\end{tabular}

${ }^{a}$ Solvent $=$ NMP. sh: shoulder peak. ${ }^{b}$ From ref 5 b.

Figure 4 shows UV-vis spectra of $\mathbf{P}(\boldsymbol{N}$-R-DPA $)$-Nis in NMP. Optical data of the polymers are summarized in Table III. The $\pi-\pi^{*}$ absorption peaks of the polymers appear at $\lambda_{\max }=347-366 \mathrm{~nm}$ for P( $N$-alkyl-DPA $)$-Ni and $310 \mathrm{~nm}$ for P(N-Bz-DPA)-Ni, respectively. The peak positions are shifted to a longer wavelength by $51-53 \mathrm{~nm}$ from those of the corresponding monomers, $\mathrm{Br}-\mathrm{C}_{6} \mathrm{H}_{4}-p-\mathrm{NR}-\mathrm{C}_{6} \mathrm{H}_{4}-p-\mathrm{Br}$. The UV-vis data of $\mathbf{P}(\boldsymbol{N}$-R-DPA $)-\mathbf{N i}$ essentially agree with that of $\mathbf{P}\left(\boldsymbol{N}\right.$-R-DPA)-Ox ${ }^{6 \mathrm{a}, \mathrm{b}}$ indicating that the latter polymer is essentially completely dedoped during work-up. P(DPA)-Ni showed the absorption peak at a somewhat longer wavelength, $\lambda_{\max }=380 \mathrm{~nm}^{5 \mathrm{~b}}$ It is reported that electronic interaction between aromatic rings via the -NR-group is possible and the electronic interaction decreases when a sterically large $\mathrm{R}$ group is attached at $\mathrm{N} .{ }^{8 c, d}$ 


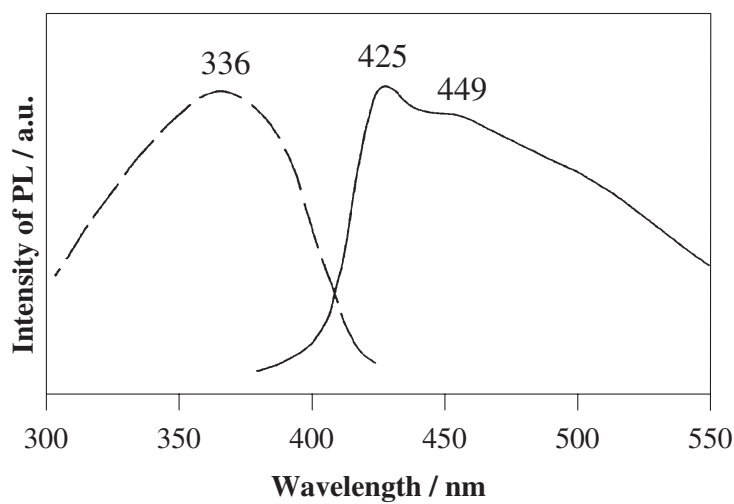

Figure 5. $\mathrm{PL}$ (solid line) and excitation (dashed line) spectra of $\mathbf{P}(\mathbf{N}-\mathrm{Hex}-$ DPA)-Ni in NMP.

Figure 5 discloses PL and excitation spectra of $\mathbf{P}(\mathrm{N}$-HexDPA)-Ni in NMP. P(N-Hex-DPA)-Ni emits blue colour in PL and shows the PL peak at $\lambda_{\mathrm{EM}}=425 \mathrm{~nm}$ with a shoulder peak at $\lambda_{\mathrm{EM}}=449 \mathrm{~nm}$. The $\lambda_{\mathrm{EM}}$ position agrees with the onset position of the UV-vis absorption band. Monitoring PL at 425 and $449 \mathrm{~nm}$ gave essentially the same excitation spectra. Other polymers were also luminescent and showed $\lambda_{\mathrm{EM}}$ in a range of 408-425 nm (Table III). These $\lambda_{\mathrm{EM}}$ values are comparable to those of P(DPA)-Ni $\left(\lambda_{\mathrm{EM}}=417 \mathrm{~nm}\right)^{5 \mathrm{~b}}$ and analogous dipyridyl amine polymers, $\left(\mathrm{C}_{5} \mathrm{H}_{3} \mathrm{~N}-\mathrm{NR}-\mathrm{C}_{5} \mathrm{H}_{3} \mathrm{~N}\right)_{\mathrm{n}}\left(\lambda_{\mathrm{EM}}=415 \mathrm{~nm}\right.$ for $\mathrm{R}=$ hexyl and $416 \mathrm{~nm}$ for $\mathrm{R}=(S)$-2-methylbutyl). ${ }^{8 \mathrm{c}} \mathbf{P}(\mathrm{N}$ R-DPA)-Nis themselves were insulating materials with electrical conductivity $(\sigma)$ below $10^{-9} \mathrm{~S} \mathrm{~cm}^{-1}$. After exposure of the polymers to an $\mathrm{I}_{2}$ vapor, the $\mathrm{Me}, \mathrm{Bu}, \mathrm{Hex}$, and $\mathrm{Bz}$ polymers showed electrical conductivity of $2.0 \times 10^{-2}, 2.4 \times 10^{-3}$, $1.7 \times 10^{-3}$, and $3.3 \times 10^{-4} \mathrm{~S} \mathrm{~cm}^{-1}$, respectively.

\section{CONCLUSION}

New alkyl derivatives of poly(diphenylamine), $\mathbf{P}(\boldsymbol{N}$-RDPA)-Nis, were prepared and characterized by IR, ${ }^{1} \mathrm{H}$ and ${ }^{13} \mathrm{C}\left\{{ }^{1} \mathrm{H}\right\} \mathrm{NMR}$, and elemental analysis. The polymers, especially the $\mathrm{Bu}$ and Hex polymers, had good solubility in organic solvents, and gave $M_{\mathrm{n}}$ values of 3400-6100 with $M_{\mathrm{w}} / M_{\mathrm{n}}=$ $1.9-2.4$ and $[\eta]$ values of $0.52-0.93 \mathrm{dL} \mathrm{g}^{-1}$. They showed good thermal stability. UV-vis data suggested expansion of the electronic system through the $-\mathrm{N}(\mathrm{R})$ - group and they showed PL peaks at about $420 \mathrm{~nm}$.

Received: April 22, 2009 Accepted: June 13, 2009 Published: July 29, 2009

\section{REFERENCES}

1. For reviews, see:

a) A. J. Heeger, Angew. Chem., Int. Ed., 40, 2591 (2001).

b) A. J. Heeger, J. Phys. Chem. B, 105, 8475 (2001).

c) A. Malinauskas, Polymer, 42, 3957 (2001).

d) A. J. Heeger, MRS Bull., 26, 900 (2001).

e) T. Hirao, Coord. Chem. Rev., 226, 81 (2002). f) A. J. Heeger, Synth. Met., 125, 23 (2001).

g) Y. S. Negi and P. V. Adhyapak, J. Macromol. Sci. Polym. Rev., 49, 35 (2002).

h) A. Pud, N. Ogurtsov, A. Korzhenko, and G. Shapoval, Prog. Polym. Sci., 28, 1701 (2003).

i) D. Nicolas-Debarnot and F. Poncin-Epaillard, Anal. Chim. Acta, 475, 1 (2003).

j) A. Malinauskas, J. Power Sources, 126, 214 (2004).

k) Y. Wang and X. Jing, Polym. Adv. Technol., 16, 344 (2005).

1) J. Huang and R. B. Kaner, Chem. Commun., 367 (2006).

m) M. Sairam, S. K. Nataraj, T. M. Aminabhavi, S. Roy, and C. D. Madhusoodana, Sep. Purif. Rev., 35, 249 (2006).

n) K. Mallick, M. J. Witcomb, and M. S. Scurrell, Gold Bull., 39, 166 (2006).

o) H. K. Hall, Jr., A. B. Padias, and H. W. Boone, J. Polym. Sci., Part A: Polym. Chem., 45, 4751 (2007).

2. a) K.-S. Ryu, K.-M. Kim, S.-G. Kang, G.-J. Lee, J. Joo, and S.-H. Chang, Synth. Met., 110, 213 (2000).

b) K.-S. Hwang, C.-W. Lee, T.-H. Yoon, and Y.-S. Son, J. Power Sources, 79, 225 (1999).

c) M. Morita, S. Miyazaki, M. Ishikawa, Y. Matsuda, H. Tajima, K. Adachi, and F. Anan, J. Power Sources, 54, 214 (1995).

d) S. Shimizu, T. Saitoh, M. Uzaura, M. Yuasa, K. Yano, T. Maruyama, and K. Watanabe, Synth. Met., 85, 1337 (1997).

e) H. Verela, S. L. de A. Maranhao, R. M. Q. Mello, E. A. Ticianelli, and R. M. Torresi, Synth. Met., 122, 321 (2001).

3. a) K. Hyodo, Electrochim. Acta, 39, 265 (1994).

b) A. Kitani, J. Yano, and K. Sasaki, J. Electroanal. Chem., 209, 227 (1986).

4. B. Wessling, Synth. Met., 93, 143 (1998).

5. a) T. Yamamoto, S. B. Kim, and T. Maruyama, Chem. Lett., 25, 413 (1996).

b) S. B. Kim, K. Harada, and T. Yamamoto, Macromolecules, 31, 988 (1998).

c) T. Yamamoto, Macromol. Rapid Commun., 21, 583 (2002).

d) S. B. Kim, Dissertation for Ph. D. degree, Tokyo Institute of Technology, 1999.

6. a) J. H. Sim, E. Ueno, I. Natori, J. Ha, and H. Sato, Synth. Met., 158, 345 (2008) and references therein.

b) L. Dao, M. T. Nguyen, and R. Paynter, Synth. Met., 41-43, 649 (1991).

c) T. Sato, K. Ogino, and R. Yamaguchi, Jpn. Kokai Tokkyo Koho, JP2000072722 (2000).

d) N. Kuroda, Y. Shikatani, Y. Shimo, N. Kataoka, and K. Matsuura, Jpn. Kokai Tokkyo Koho, JP01006060 (1989).

e) T. Hagiwara, M. Yamaura, and K. Iwata, Nippon Kagaku Kaishi, 1791 (1989).

7. a) S. Grigalevičius, V. Getautis, J. V. Gražulevičius, V. Gaidelis, V. Jankauskas, and E. Montrimas, Mater. Chem. Phys., 72, 395 (2001). b) T. Yasuda, T. Imase, and T. Yamamoto, Macromolecules, 38, 7378 (2005).

c) G. Blazys, S. Grigalevičius, J. V. Gražulevičius, V. Gaidelis, V. Jankauskas, and V. Kampars, J. Photochem. Photobiol. A, 174, 1 (2005).

d) Y. Morisaki, N. Wada, and Y. Chujo, Polymer, 46, 5884 (2005).

e) R. Zheng, M. Häussler, H. Dong, J. W. Y. Lam, and B. Z. Tang,

Macromolecules, 39, 7973 (2006).

f) C. H. Zhao, A. Wakamiya, and S. Yamaguchi, Macromolecules, 40, 3898 (2007).

g) K. Idzik, J. Sołoducho, J. Cabaj, M. Mosiadz, M. Łapkowski, and S. Golba, Helv. Chim. Acta, 91, 618 (2008).

h) G. Zhou, M. Baumgarten, and K. Müllen, J. Am. Chem. Soc., 129, 12211 (2007).

i) S. Beaupré, J. Dumas, and M. Leclerc, Chem. Mater., 18, 4011 (2006).

j) Y. Morisaki, H. Chen, and Y. Chujo, Polym. Bull., 52, 141 (2004).

8. a) H. J. Bolink, E. Coronado, A. Forment-Aliaga, and C. J. Gómez- 
García, Adv. Mater., 17, 1018 (2005).

b) M. Horie, I. Yamaguchi, A. Tanimoto, and T. Yamamoto, Chem. Lett., 34, 570 (2005).

c) I. Yamaguchi, E. Fujinaga, T. Ozeki, and T. Yamamoto, Bull. Chem. Soc. Jpn., 77, 1773 (2004).

d) M. Horie, I. Yamaguchi, and T. Yamamoto, Macromolecules, 39, 7493 (2006).

e) M. T. Nguyen and L. H. Dao, J. Chem. Soc., Chem. Commun., 1221 (1990).
9. B. Bogdanovic, M. Kröner, and G. Wilke, Liebigs Ann. Chem., 699, 1 (1966).

10. J. Berthelot, C. Guette, P. L. Desbene, J. J. Basselier, D. Chaquin, and D. Masure, Can. J. Chem., 67, 2061 (1989).

11. a) T. Yamamoto, T. Maruyama, Z. H. Zhou, T. Ito, T. Fukuda, Y. Yoneda, F. Begum, T. Ikeda, S. Sasaki, H. Takezoe, A. Fukuda, and K. Kubota, J. Am. Chem. Soc., 116, 4832 (1994).

b) T. Yamamoto and T. Koizumi, Polymer, 48, 5449 (2007). 